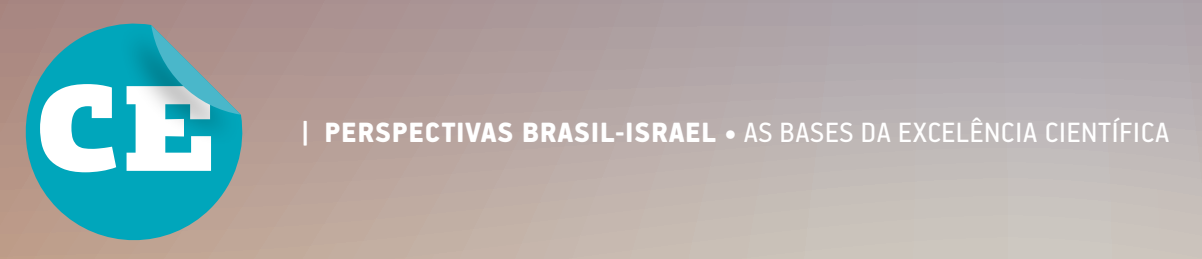

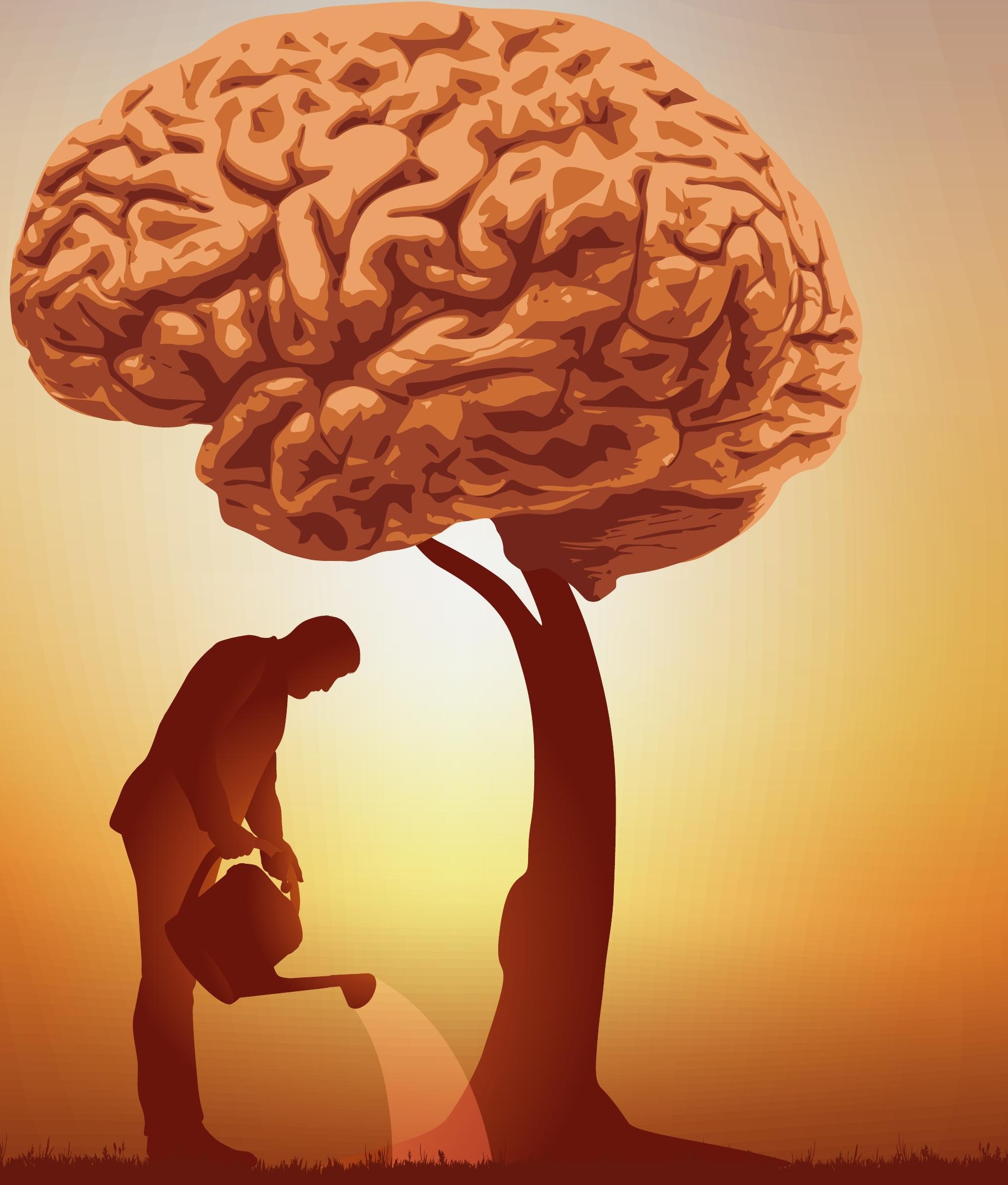




\section{AS BASES DA EXCELÊNCIA CIENTÍFICA}

\section{O Instituto Weizmann mostra que ciência de ponta se faz com pesquisadores bem formados, livres para criar, em conexão com a prática e de todas as partes do mundo, inclusive do Brasil.}

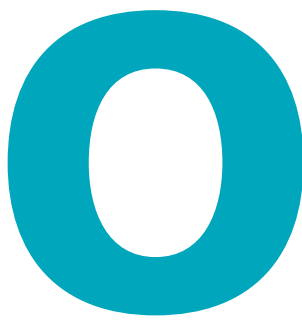

s desafios que a humanidade enfrenta são enormes: mudanças climáticas, crises energéticas, problemas causados por escassez ou abundância de alimentos, a pandemia da COVID-19, enfermidades como diabetes, câncer, doenças neurodegenerativas, depressão e estresse. Para continuarmos avançando rumo a uma vida melhor e mais longa, teremos que lidar com esses problemas com base na ciência e no maior patrimônio da sociedade: a capacidade intelectual das pessoas.

O capital humano é o recurso singular que Chaim Weizmann, químico de renome e primeiro presidente de Israel, visionou para ser a espinha dorsal para a economia e o sucesso do país, ao fundar o Instituto Weizmann de Ciências. Localizado na cidade de Rehovot, em Israel, o instituto é líder no mundo em pesquisa básica e excelência científica, classificado em segundo lugar em qualidade de pesquisas pela revista Nature. O instituto dedica-se a promover os principais caminhos de investigação em uma variedade de campos, buscando formas de combater doenças, melhorar a qualidade de vida, criar tecnologias e proteger o meio ambiente. Além de formar parte substancial da liderança científica de Israel, o Weizmann promove a educação básica por meio de parcerias com a rede escolar e oferece conhecimento científico ao público geral promovendo palestras e debates abertos.

\section{CENTRO DE EXCELÊNCIA}

Fundado em 1934, o Instituto Weizmann mantém ainda hoje os pilares que o levaram ao sucesso: cientistas de máximo padrão de excelência, motivados com liberdade para trabalhar suas curiosidades científicas, suportados por uma infraestrutura de equipamentos, materiais e processos de primeira qualidade e em ambiente de intensa colaboração. A isso se soma uma estrutura financeira e administrativa de excelência e a fórmula fica completa.

Os pesquisadores do instituto são responsáveis por terem inventado a amniocentese, remédios para esclerose múltipla (Copaxone ${ }^{\circledR}$ ), nanomateriais e o algoritmo que torna as operações bancárias seguras atualmente (a criptografia RSA Rivest-Shamir-Adleman). Em 1954, a instituição projetou e construiu o primeiro computador de Israel, o WEIZAC (si- 


\section{FUNDAMENTOS DA EXCELÊNCIA CIENTÍFICA DO INSTITUTO WEIZMANN}

Infraestrutura. Os equipamentos e ferramentas são de última geração e o uso de inteligência artificial é obrigatório.

Recrutamento. Há captação permanente de talentos, independentemente de vagas a serem preenchidas.

Liberdade. Não se diz às melhores mentes o que devem pesquisar. Os resultados acontecem com a liberdade de os cientistas perseguirem suas ideias, sem amarras a escopos de projetos predefinidos.

Multidisciplinariedade. Projetos e iniciativas têm liberdade para compor equipes de cientistas de múltiplas disciplinas.

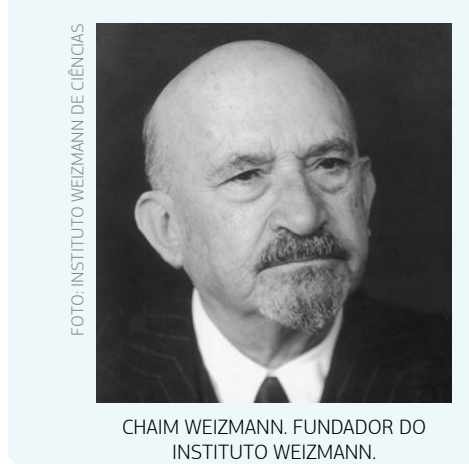

INSTITUTO WEIZMANN.
Intercâmbio. Cientistas são incentivados a realizarem estágios em outras instituições internacionais relevantes. Os projetos de pesquisa contam com revisão de qualidade de comitês compostos também por cientistas renomados de outras instituições. Dos alunos de pós-doutorado, apenas $30 \%$ são israelenses, os demais vêm de todas as partes do mundo, inclusive do Brasil.

Diversidade. Programas como o Advancing Women in Science e a existência do Diversity and Inclusion Office são exemplos de como instrumentalizar e viabilizar a diversidade de pessoas.

Flexibilidade. As políticas de recursos humanos contemplam busca de equilíbrio entre desafios pessoais, profissionais e familiares dos cientistas. gla para Weizmann Automatic Computer), o que lançou as bases para a indústria de software no país. Hoje, cientistas do centro estão projetando um computador quântico que vai revolucionar a capacidade tecnológica da ciência da computação. O mesmo espírito pioneiro gerou a construção do primeiro acelerador de partículas, um dos ícones do instituto.

O Instituto Weizmann foi o primeiro a realizar pesquisas sobre câncer em Israel. Esses estudos já deram frutos no diagnóstico e tratamento em diversos tipos de tumor, como a iniciativa Banco de Tumores Weizmann-Brasil, que ajuda pesquisadores brasileiros a descobrirem como vários genes controlam o crescimento de tumores e a definir tratamentos personalizados. As pesquisas em neurociências, que terão impulso com o futuro Instituto do Cérebro e Neurociências, são berço de conhecimento e soluções para doenças neurodegenerativas como alzheimer, esclerose lateral amiotrófica (ELA) e parkinson, assim como para condições como autismo, depressão e ansiedade.

Dos laboratórios emergiram fármacos de sucesso, métodos diagnósticos sofisticados, sensores minúsculos e vacinas, como a da hepatite B. Em um exemplo de pesquisas, ao decifrar a estrutura do ribossomo, a Prêmio Nobel Ada Yonath revelou mecanismos de resistência a antibióticos, abrindo caminho para o design de novos medicamentos. Mais avanços virão do novo projeto Fronteiras do Universo, que abrange desde física das partículas até exploração espacial e astrofísica, e dos 60 grupos de pesquisa que desde o início da pandemia atenderam ao chamado de redirecionar seu trabalho para o coronavírus.

\section{PONTE COM O BRASIL}

Mas o futuro não fica dentro das fronteiras de Israel. Os desafios à nossa frente deixam claro que os problemas mais importantes do planeta não podem ser enfrentados com esforços unicamente locais.

A cooperação internacional no mundo da ciência sempre foi um instrumento para propiciar o avanço do conhecimento. No caso do Brasil, a interface do Weizmann com o país é impulsionada há longa data pela organização Grupo de Amigos do Weizmann do Brasil. Hoje, com a coordenação científica a cargo de Regina P. Markus e presidida por Mario Fleck, suas atividades visam apoiar a excelência do instituto no intercâmbio com o Brasil.

O Grupo de Amigos do Weizmann do Brasil incentiva a conexão de cientistas brasileiros, israelenses e de todo 


\section{Os desafios à nossa frente deixam claro que os problemas mais importantes do planeta não podem ser enfrentados com esforços unicamente locais e, assim, o Instituto Weizmann exerce suas atividades em sintonia com diversas organizações em mais de 100 países.}

o mundo, seja por meio de financiamento de agências de fomento, como a Fundação de Amparo à Pesquisa do Estado de São Paulo (FAPESP), ou de instituições privadas, como o Instituto Serrapilheira. Também promove o intercâmbio de pesquisadores e ideias, com a Universidade de São Paulo (USP), o Hospital Israelita Albert Einstein, o Instituto Oncoclínicas, apenas para citar alguns exemplos. Ao longo dos anos, apoiou inúmeros projetos: de energias renováveis ao câncer, de neurociências a física, e concedeu bolsas de estudo a mais de 90 estudantes e pesquisadores.

É essencial também pensar no amanhã, e para isso a missão de capacitar a nova geração de cientistas e educar cientificamente a população em geral é uma das prioridades do instituto. Com mais de 70 programas destinados a crianças e jovens, o Weizmann se preocupa desde sempre com o começo dessa corrente. Os cientistas não baterão às portas da ciência aos 30 anos prontos para essa jornada. É necessário investir para que as crianças e jovens tenham a exposição necessária e eficiente para pavimentar o caminho dos cientistas do amanhã.

Desde 1982, o Grupo de Amigos do Weizmann do Brasil reúne patrocinadores e colaboradores para incluir os brasileiros nesse cenário. Todos os anos, uma banca de professores de renome dedica-se a selecionar estudantes brasileiros do primeiro ano de faculdade para uma imersão de um mês no Weizmann. A seleção chega a todos os estados brasileiros e alcança todos os cursos com viés em ciência, que enviam seus melhores talentos para vivenciar essa ciência pulsante e de ponta. Em Israel, o seleto grupo de jovens cientistas brasileiros se junta a um grupo de colegas do mundo todo, que também participam do programa. Ali está a semente: as melhores mentes, com diferentes origens e backgrounds, nos melhores laboratórios, questionando, experimentando, trocando conhecimento, livres das amarras do aqui e agora, respondendo às perguntas mais essenciais para que o desconhecido seja conhecido.
Mas não basta que o desconhecido seja conhecido. A produção desse conhecimento precisa gerar impacto. Em 1959, isso já estava muito claro com a criação da Companhia Yeda (palavra em hebraico que significa conhecimento), o braço de transferência tecnológica, pioneiro em Israel e um dos primeiros do mundo com esse conceito. Desde então, a tangibilidade dos resultados desse impacto pode ser traduzida em números, e em royalties. Em 2020, a venda de produtos, tecnologias e medicamentos baseados em patentes do Weizmann representou mais de 36,5 bilhões de dólares em receita para as empresas que licenciaram as patentes, a indústria farmacêutica principalmente.

A próxima revolução científica será promovida por cientistas que têm uma visão multidisciplinar da ciência, a capacidade de enfrentar adversidade, a infraestrutura para trabalhar e a liberdade de pensar. As melhores mentes também estão no Brasil, e precisamos somar esforços para que essa colaboração seja cada vez maior e mais sólida para continuar a avançar no que é o slogan do instituto: Ciência para Benefício da Humanidade.

Os tempos atuais mostram que, com todo o avanço do conhecimento nas últimas décadas, os desafios para a humanidade ficaram ainda maiores. Apenas com a integração e colaboração entre mentes e instituições de alto padrão, as novas fronteiras do conhecimento poderão melhorar a vida para o ser humano e para seu planeta.

\footnotetext{
PARA SABER MAIS:

- Site do Grupo de Amigos do Weizmann do Brasil. Disponivel em: amigosdoweizmann.org.br/

Small Institute, Outsized Impact. Weizmann Institute of Science, 2019. Disponivel em wis-wander.weizmann.ac.il/awards-and-appointments/small-institute-outsized-impact Weizmann-Brazil Tumor Bank. Weizmann Brazil. Disponivel em: amigosdoweizmann.org.br stage/banco-de-tumores

Ada E. Yonath. Prize presentation. The Nobel Prize, 2009. Disponivel em: nobelprize.org/prizes/chemistry/2009/yonath/prize-presentation

Mario Fleck > Presidente do Grupo de Amigos do Weizmann do Brasil > mario.fleck@acnext.com

Daniel Schmit > CEO para América Latina do Instituto Weizmann de Ciências >
} daniel.schmit@weizmann.ac.il 